رابطه ارزش افزوده بخش آب با ارزش افزوده بخشهاى كثاورزى،

صنعت و برق در استان مازندران

\author{
عبداله درزى نفت جالى '، ساره رفيعىراد`، مجتبى خوشروش '*، احمد عسكرى' \\ محمدرضا بابايیى "و حسينعلى زبردست رستمى

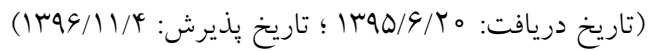

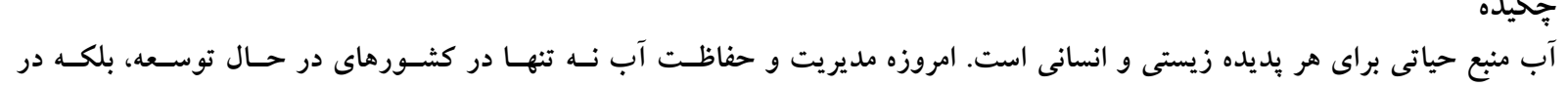

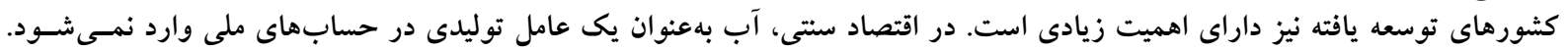

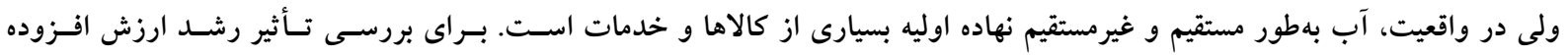

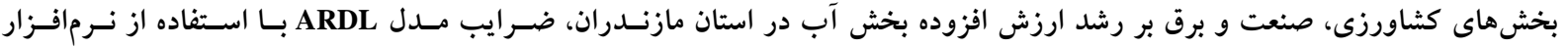

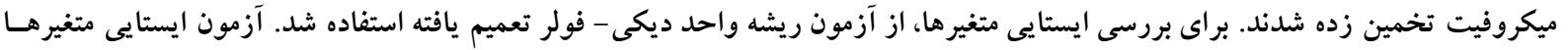

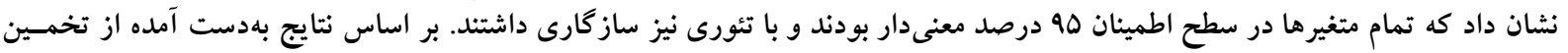

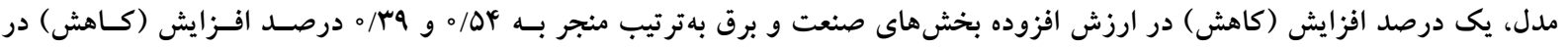

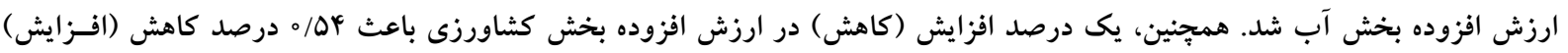

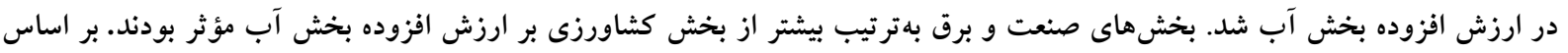

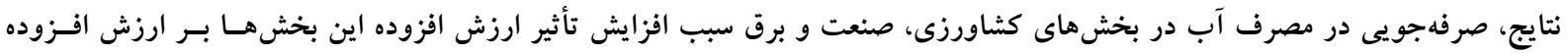
بخش آب مىشود.

وازههاى كليدى: اقتصاد، توليد، كالا، مدل ARDL

\footnotetext{
ا. گروه مهندسى آب، دانشكده مهندسى زراعى، دانشگاه علوم كثاورزى و منابع طبيعى سارى، سارى r. كروه اقتصاد كشاورزى، مؤسسه يُزوهشهاى برنامهريزى اقتصاد كشاورزى و توسعه روستايى، تهر ان

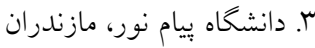

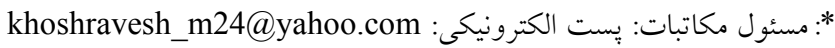


بيشترين استفاده از منابع آب شيرين دنيـا در بخـش كشـاورزى

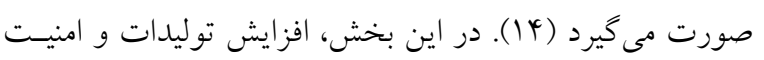

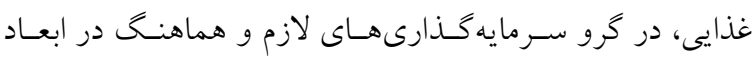

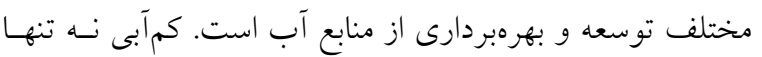

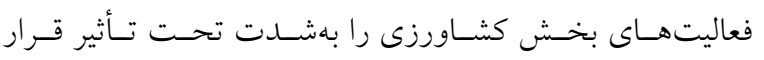

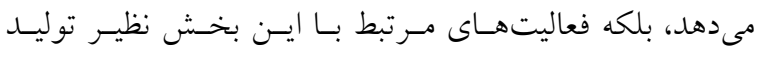

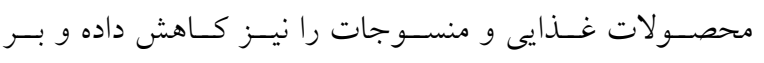

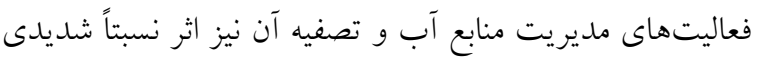

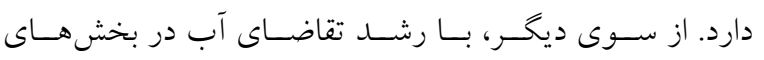
كشاورزى، شرب و صنعت و افـزوده شــدن تقاضـاهاى جديـــ

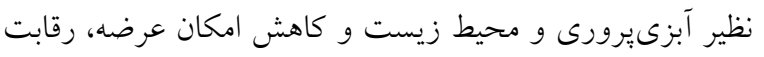

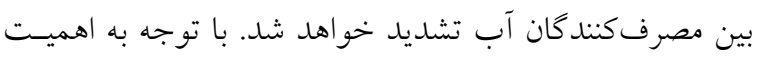
بخش كشاورزى در اقتصاد ايران و بهخصوص جامعه روستايى،

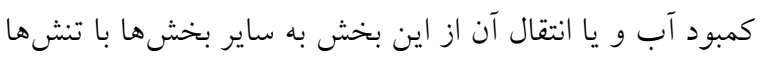

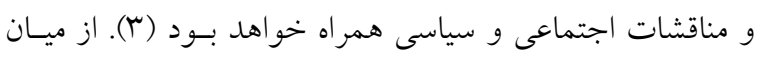

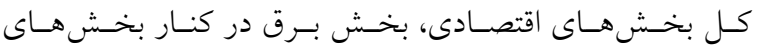

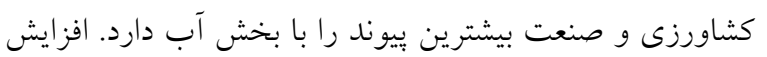

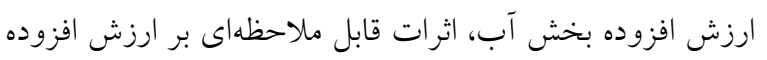
بخش برق داد (IV) نتايج تحقيقـات مركـز مطالعـات محسيط زيستـ داد دانشـاه

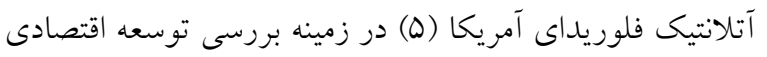

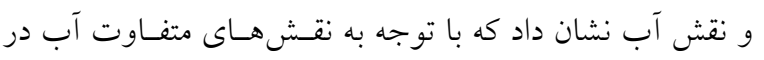
زندكى بشر، مشخص كردن نقش دقيسق آب در توسعه اقتصـاد

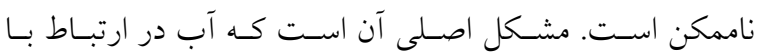

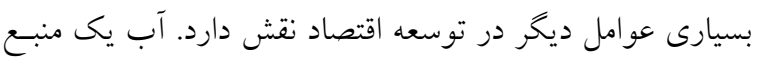

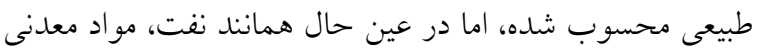
و جهوب يك كالاى اساسى نيز هست. استخراج، تصفيه و توزيع

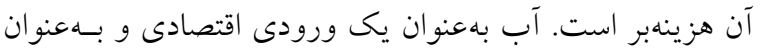

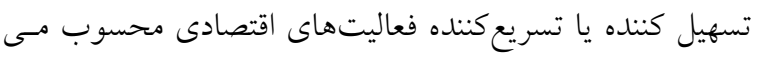

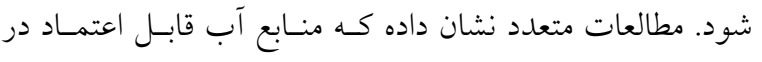
رشد توليد ناخالص داخلمى، سهم داشته و كمبود آب به ركود و و

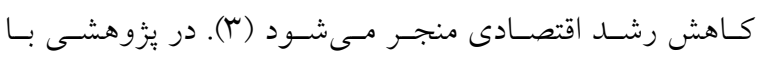

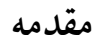
آب يك منبع طبيعى تجديدشونده است كه بـا استفاده صسحيح

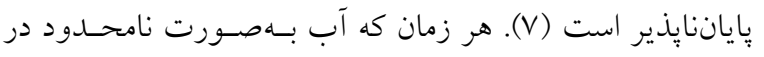

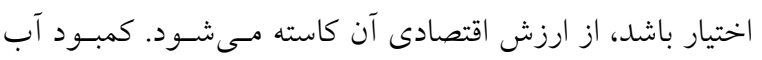

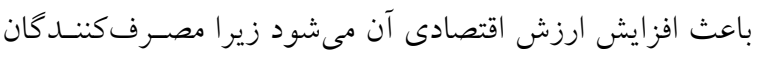

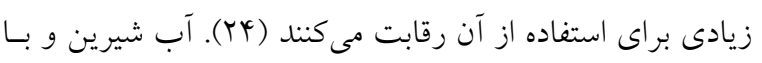

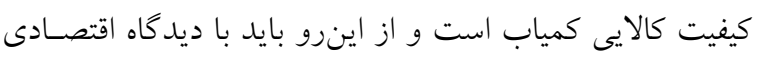

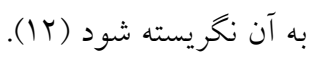

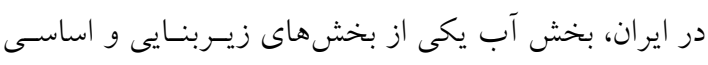

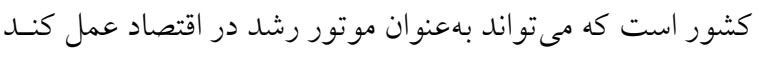

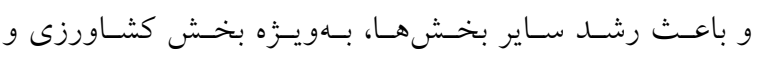

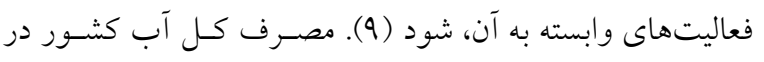
حدود NN/Q ميليارد متر مكعب در سال است كـه بـ/ه م ميليسارد

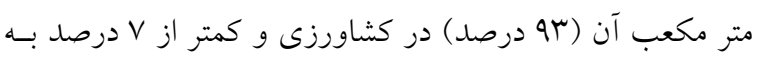

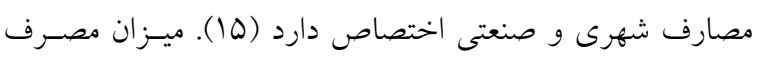

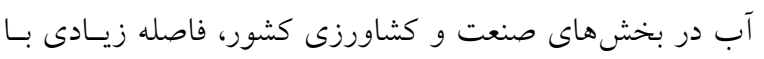

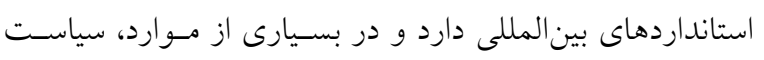
بهينهسازى مصرف، به درستى و در بخش مناسب اعمـال نشـده ودئ

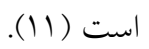

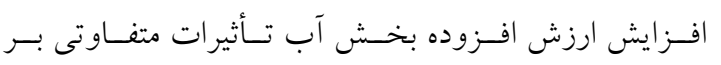

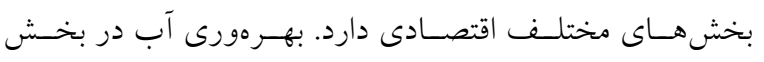

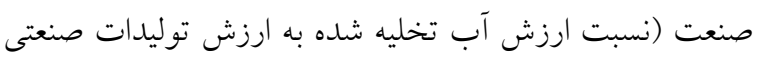

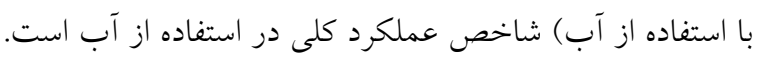

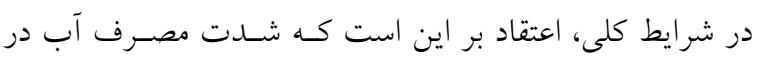
بخش صنعت بهصورت ارزش افزوده صنعت بهازاى هـر واحســ

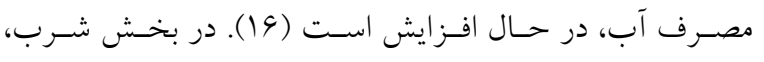

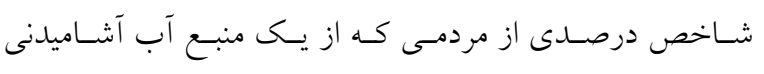

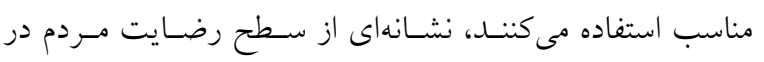

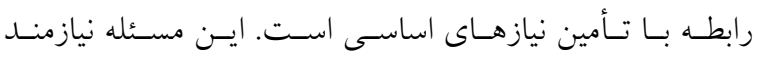

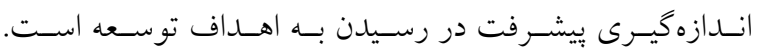

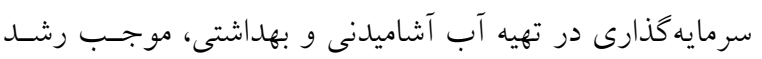
اقتصادى مىشود (IV) - (1V). 
مثبت و منفى بر ارزش افزوده بخش صنعت دارنسـ. آهنخــى و

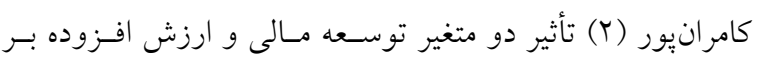

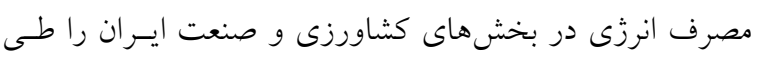

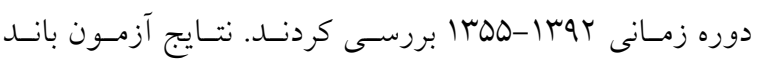
ARDL

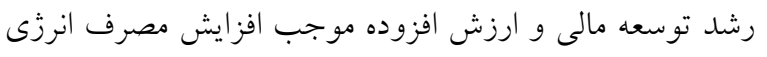
شدند. مرور تحقيقات انجام شده نشان مىدهد كه تاكنون نقش آب درن

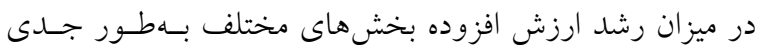

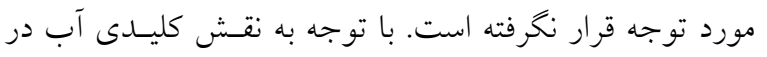

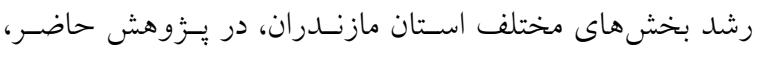

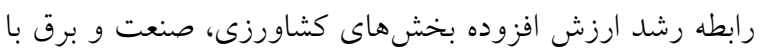

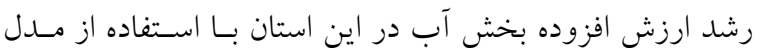

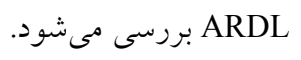

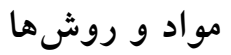

براى انجـام ايـن تحقيـق، دادههـاى ارزش افـزوده بخـشهــى

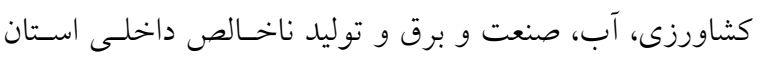

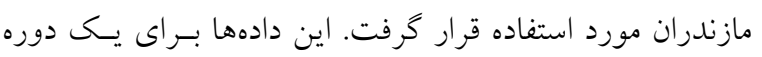

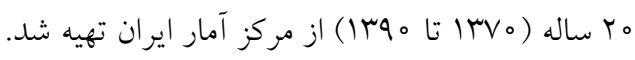

\section{روش خودتوضيح بردارى با وقفههاى گسترده}

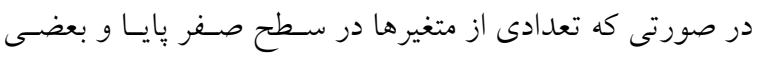

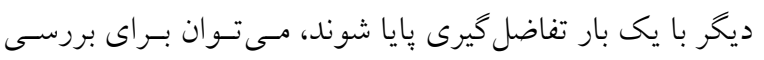

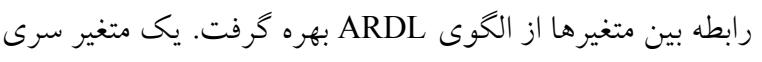

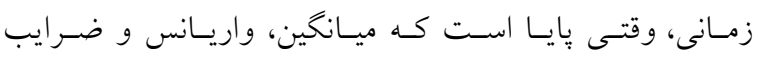

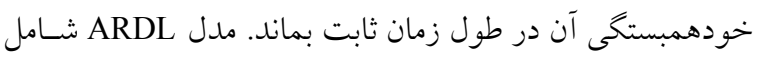

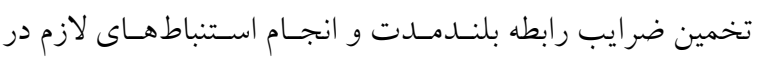
مورد اين ضرايب است. براى تصميم كيرى در مورد رد و يا قبول

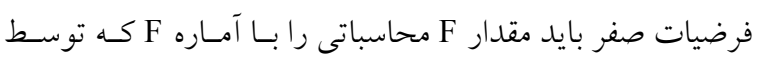

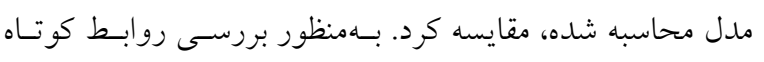

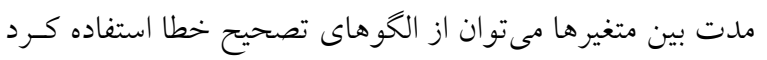

رويكردى سيستمى و كلنخر، آثار كمبود آب در اقتصاد كشور با

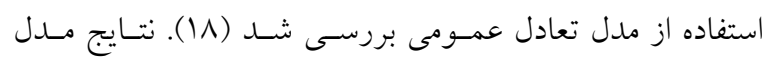

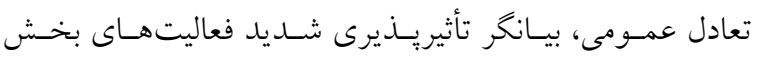

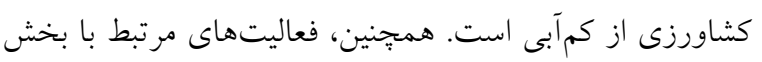

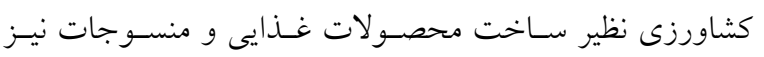
كاهش سطح توليد را نشان مىدهد.

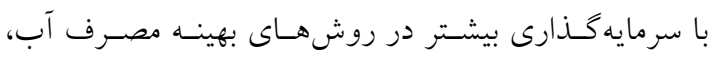
توليد برخى بخشهاى اقتصادى وابسته به آب افـزايش يافتسه و

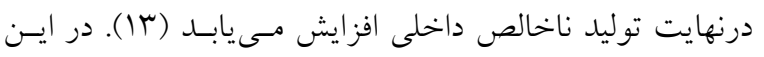

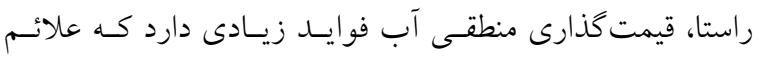

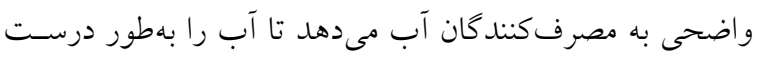

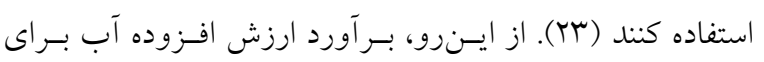

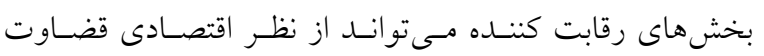

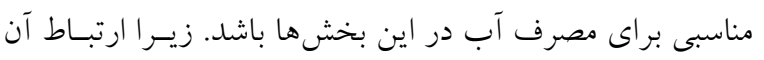

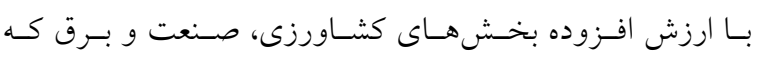

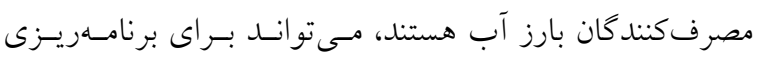

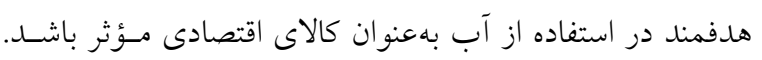

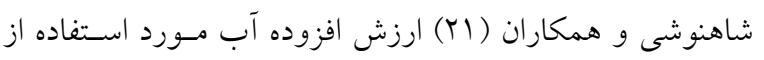

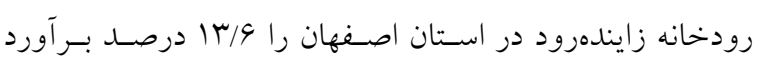

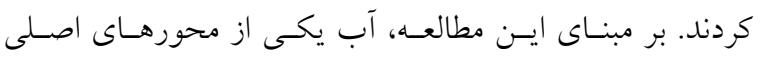

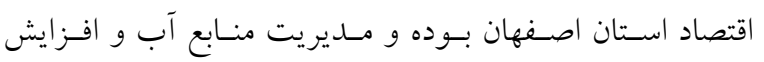

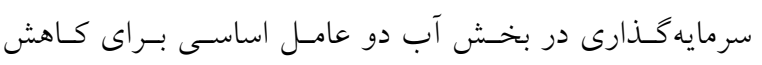

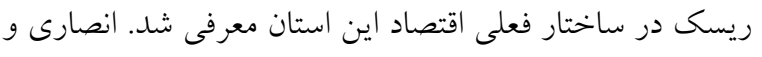

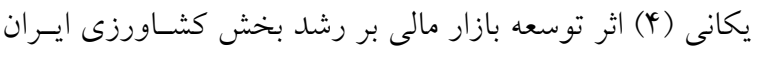

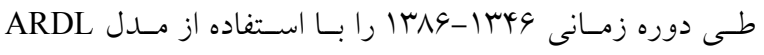

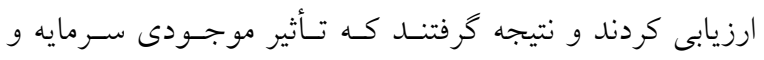

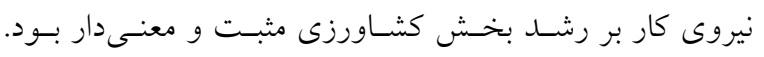

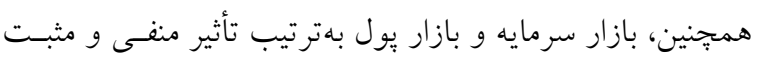

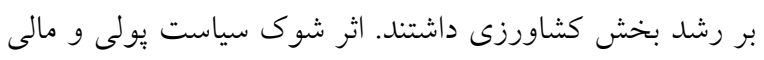
بر ارزش افزوده بخش صنعت و معدن در ايران توسط بـراداران

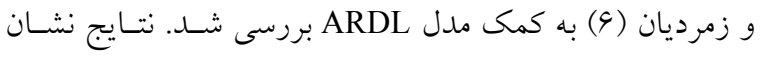
داد كه شوى مثبت و منفى سياست يولى و مالى بهترتيب اثـرى 
انحر اف معيار ضرايب مذكور تقسيم شـود. لـذا، آمـاره آبــراى

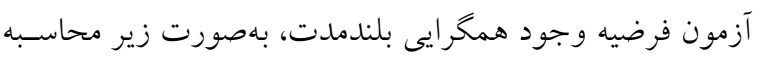
مىشود: $\tau=\frac{\sum_{\mathrm{k}=1}^{\mathrm{p}} \hat{\phi}_{\mathrm{i}}-1}{\sum_{\mathrm{k}=1}^{\mathrm{p}} \delta_{\phi_{\mathrm{i}}}}$

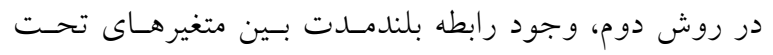

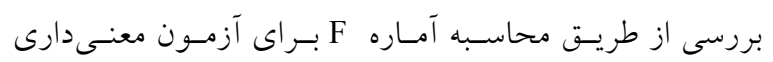

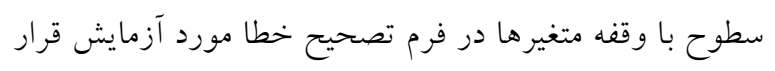

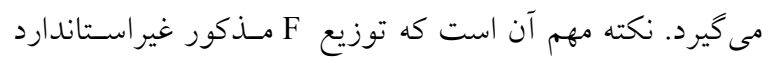

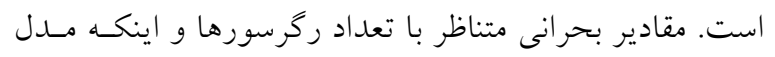

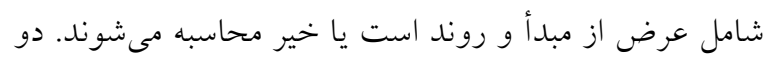

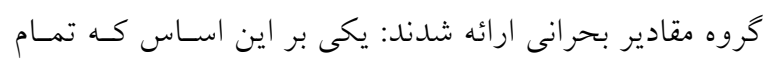

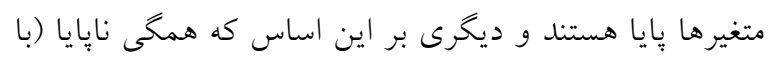

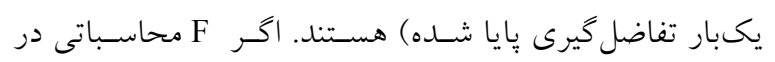

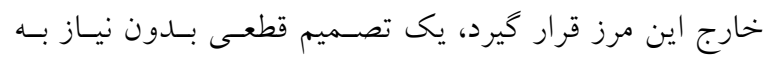

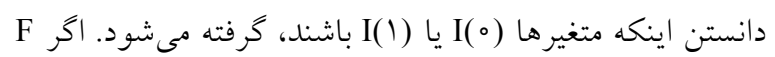

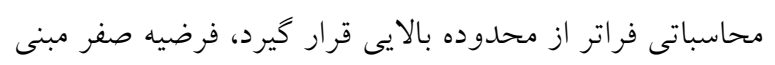

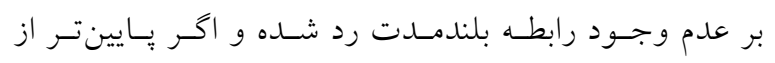

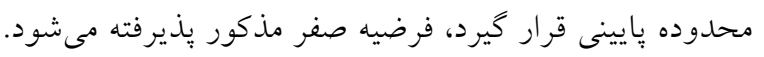

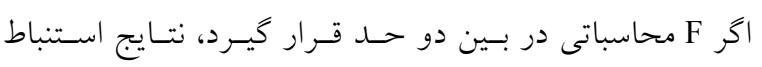

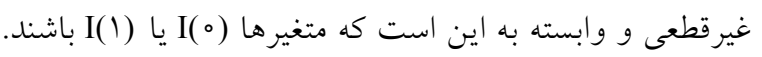

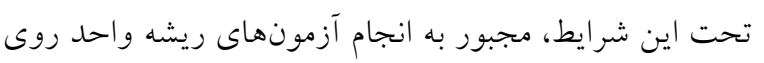

$$
\text { متغيرها هستيم. }
$$

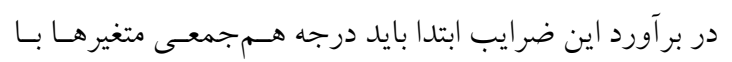

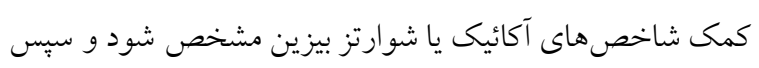

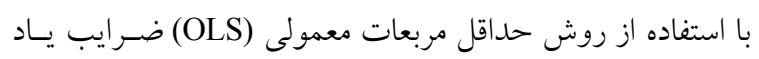

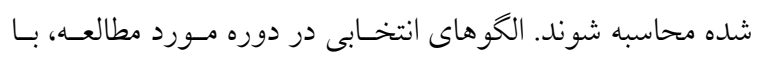

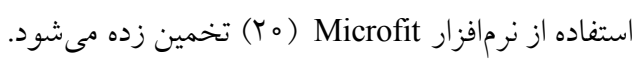

\section{نتايج و بحث} معمولاً، در دانش اقتصاد، وقتى قرار باشد ساختار اقتصادى يـى لـ .(r $\left(Y, r_{0}\right)$

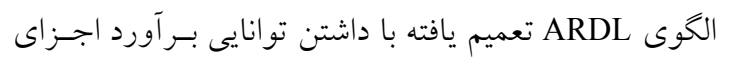

$$
\text { كو تاهمدت و بلندمدت به شرح زير است (^): }
$$

$\phi(L, P) Y_{t}=\sum_{i=1}^{k} b_{i}\left(L, q_{i}\right) X_{i t}+c^{\prime} W_{t}+u_{t}$

$\phi(\mathrm{L}, \mathrm{P})=\left(1-\phi_{1} \mathrm{~L}-\phi_{\mathrm{Y}} \mathrm{L}^{r}-\ldots-\phi_{\mathrm{P}} \mathrm{L}^{\mathrm{P}}\right)$

$b_{i}\left(L, q_{i}\right)=b_{i 。}+b_{i 1} L+b_{i r}+\ldots+b_{i_{i}} L^{q}$ $\mathrm{i}=1, \mathrm{r}, \ldots ., \mathrm{k}$

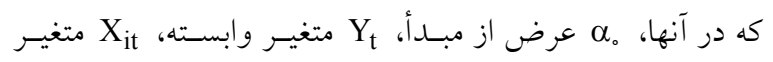

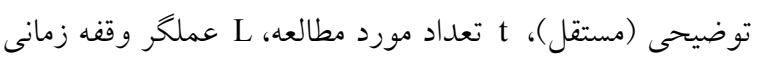

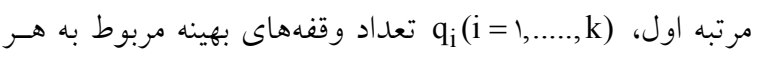
يك از متغيرهاى توضيحى، k تعداد متغيرهاى توضسيحى بـهـ كار

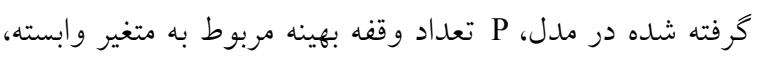

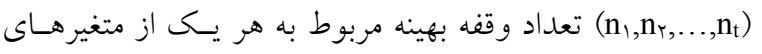

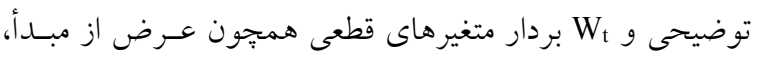

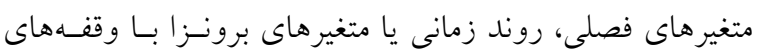

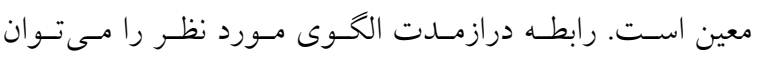
بلصورت زير بيان كرد:

$\theta_{1}=\frac{b_{i}^{\prime}\left(1, q_{i}\right)}{1-\hat{\phi}(1, p)}=\frac{\hat{b}_{i_{0}}+\hat{b}_{i 1}+\ldots+\hat{b}_{i q}}{1-\hat{\phi}_{1}-\ldots-\hat{\phi}_{\mathrm{p}}}$

براى بررسى اينكه رابطه بلندمدت حاصل از ايسن روش كـاذب

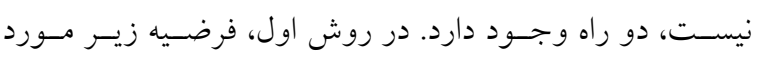

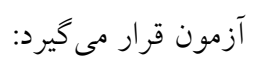

$\mathrm{H}_{\circ}=\sum_{\mathrm{i}=1}^{\mathrm{p}} \phi_{\mathrm{i}}-1 \geq 0$

$\mathrm{H}_{,}=\sum_{\mathrm{i}=1}^{\mathrm{p}} \phi_{\mathrm{i}}-1 \leq 。$

فرضيه صفر بيانكر عدم وجود هم انباشتخى يـا رابطـهـه بلندمـــت

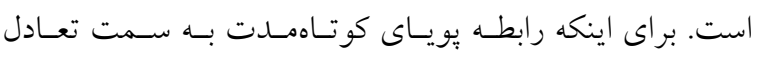

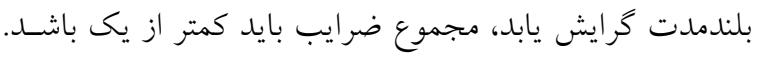

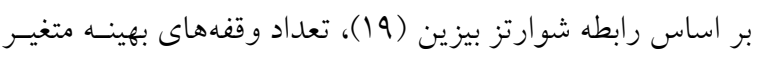

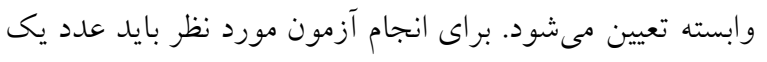

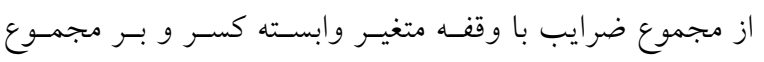




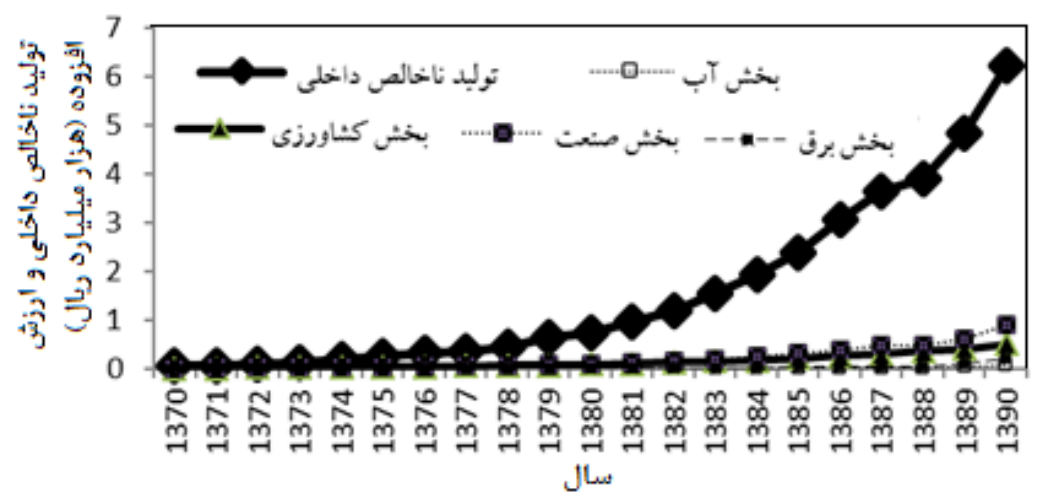

شكل ا. ارزش افزوده بخشهاى مختلف در توليد ناخالص داخلى استان مازندران (هزار ميليارد ريال)

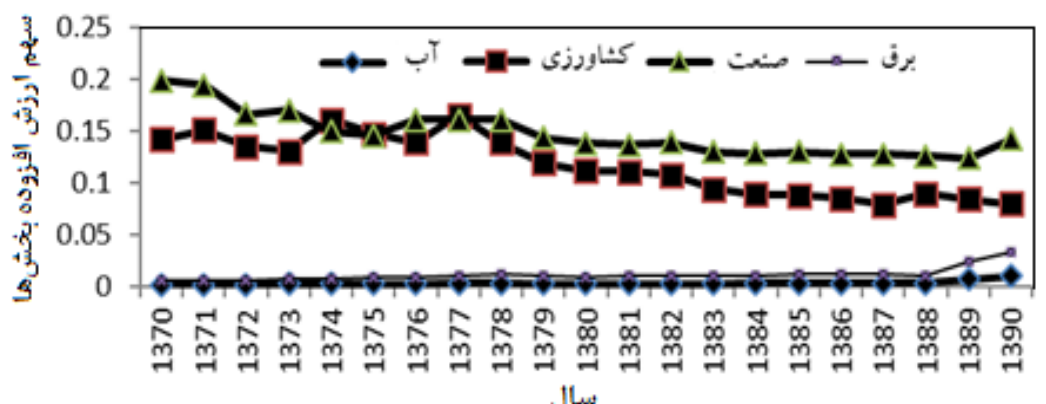

شكل r. مقايسه سهم ارزش افزوده بخشهاى مختلف در توليد ناخالص داخلى استان مازندران

ملاحظـهاى برخـوردار نبـود. متوسـط سهم بخـشهــاى آب،

كشاورزى، صنعت و برق از توليد ناخالص داخلسى در طـى ro

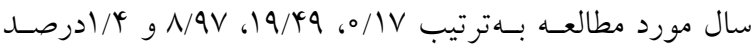

رابطه رشد ارزش افزوده بخش آب بـا رشــد ارزش افـزوده

$$
\text { بخش هاى كشاورزى، صنعت و برق }
$$

ارزش افزوده بخشهــاى مختلـف اقتصـاد بــر توليـــ ناخـالص داخلى تأثيرات متفاوتى دارد. در اين مطالعه، براى بررسى رابطه بين رشد ارزش افزوده بخش آب با رشد ارزش افـزوده بخـش هاى كشـاورزى، صـنعت و بـرق در اسـتان مازنسـدران از مــل ARDL استفاده شد. سيس، نتايج تخمين مورد تحليل و بررسى واقع شد. قبل از تخمين مدل، براى آزمون ايستايى متغيرهـا، از آزمون ريشه واحد ديكى - فولر تعميم يافته اسـتفاده شـد. نتـايج آزمون ديكى - فولر تعميم يافته در جدول (1) ارائه شـده اسـت.
جامعه بررسى شـود، اقتصـاد ملسى آن جامعسه در قالـب توليـد ناخالص داخلى يا GDP بررسى مىشود تا مشـخص شـود كـهـ سهم بخشهاى مختلف درآمدزايى در اقتصاد آن جامعه جِّـدر اسـت. در طـى دوره مطالعـه، توليــد ناخــالص داخلسى اسـتان مازندران بهطور متوسط r ا درصــ از توليـــ ناخـالص داخلسى كشور را به خود اختصاص داد. ارزش افـزوده بخـشهــــ آب، كشاورزى، صنعت و برق و سهم هر يـك از ايسن بخـشهـــا در توليد ناخالص داخلى استان مازندران بهترتيب در شكل هاى (1)

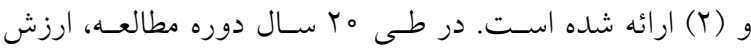
افزوده بخشهاى صـنعت و كشـاورزى در اسـتان مازنـدران از ارزش افزوده ساير بخشها بيشتر بود و بهطور متناوب افـزايش يافت. سهم ارزش افزوده بخشهاى آب و برق تقريباً ثابت بود. با اين وجود، ارزش افزوده بخش آب در بايينترين سطح قـرار داشت. در خلال جند سال اخير، ارزش افـزوده بخـش بــرق از رشدى جزئى برخوردار بود و سـهم بخـش آب از رشــ قابـل 
نشريه علوم آب و خاك (علوم و فنون كشاورزى و منابع طبيع) / سال بيست و سه / شماره اول / بهار شجr|

\begin{tabular}{|c|c|c|c|}
\hline \multicolumn{4}{|c|}{ جدول ا. نتايج بررسى ايستايى متغيرها با استفاده از آزمون ديكى - فولر تعميم يافته } \\
\hline با عرض از مبدأ و بدون روند & با عرض از مبدأ و روند & متغير & سطح \\
\hline$-r / \Lambda Y$ & $-r / v G$ & dRVAW & \multirow{4}{*}{ سطح صفر } \\
\hline$-\varphi / \varphi V$ & $-r / 99$ & dRVAA & \\
\hline$-r / \Lambda \mu$ & $-\psi / V$ & dRVAI & \\
\hline$-Q / \Delta V$ & $-Q / \uparrow V$ & dRVAE & \\
\hline - & $-1 / 9$ & dRVAW & \multirow{4}{*}{ 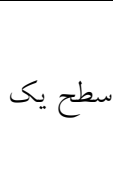 } \\
\hline$-r / v{ }^{c}$ & - & dRVAA & \\
\hline$-Y / Q$ & $-r / 4 r$ & dRVAI & \\
\hline$-r / V Q$ & $-r / v i$ & dRVAE & \\
\hline
\end{tabular}

نشاندهنده اين است كـه هو درصـد تغييـرات در ارزش افـزوده

بخش آب توسط متغيرهاى توضيحى موجسود در مـدل توضسيح داده شده است.

يس از تخمين معادله ARDL، بايد از وجود همجمعىى بـين متغيرهـا اطمينـان حاصـل كـرد. جنـانجهـه مجمـوع ضـرايب متغيرهاى با وقفه مربوط به متغير وابسته كو جكىتر از يك باشد،

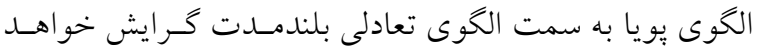
داشت. آماره t براى مسـل تخمسين زده شــه بـهــورت زيـر محاسبه شد: $\mathrm{t}=\frac{-0 / 4 \Lambda-1}{\circ / 4 V}$

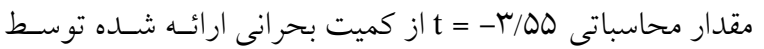
بنرجى و همكاران (ه) در سطح اطمينان ه9 درصد بيشتر اسـت. بنابراين، فرضيه صفر مبنى بر عدم رابطه بلندمدت رد و وجود آن يذيرفته مىشود. يس از اطمينان از وجود رابطـه بلندمــت ايسـن رابطه تخمين زده شد. نتايج حاصل از تخمين معادله بلندمـدت در جدول r نشان داده شده است. نتايج نشان مىدهد كـه رشـد ارزش افزوده صنعت، كشاورزى و انرزى بـهنترتيب بـا ضـرايب

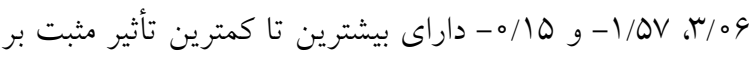

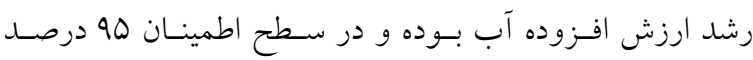

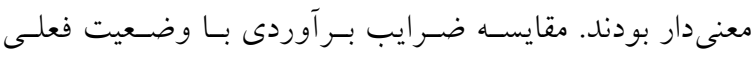
اقتصاد كشور نشان مىدهد كه بخش صنعت در مقايسه با سـاير بخشهاى در نظر كرفته شـده، تـأثير بيشـترى بـر رشـــ ارزش افزوده بخش آب دارد.
بر اساس اين آزمون، فرض صفر وجود ريشه واحد براى تمـامى متغيرها، بهجز انرزى رد نشد. با تكرار آزمهون در مـورد تفاضـل مرتبه اول متغيرها، بِ از يكبار تفاضـل گيـرى، تمـام متغيرهـا ايستا شدند. با توجه بـه ايستايى دادههـا، اسـتفاده از روش سـنتى OLS مقــدور نيسـت. بنـابراين، از روش خودباز گشـت بــا وقفـههـاى توزيعى استفاده شد (^). در اين روش، توجه به درجسه ايسـايى متغيرها اهميتى ندارد. همجنين، با تعيين وقفههاى مناسـب بـراى متغيرها، مدل مناسب و منحصر بـهـ فـردى بــدون يـيش داورى و استفاده از نظريههاى اقتصاد انتخاب مىشود. بهمنظور برآورد تـأثير رشـد ارزش افـزوده بخـش آب روى آته ارزش افزوده بخش هاى كشاورزى، صـنعت و بـرق، فـرم مــل ARDL براى تحقيق حاضر بهصورت زير است: $\operatorname{RVAW}=\alpha_{\circ}+\sum_{j=o}^{n} \beta_{1 j} \cdot \operatorname{RVAA}_{t-j}+\sum_{j=o}^{n} \beta_{r j}$.

$$
\operatorname{RVAI}_{t-j}+\sum_{j=o}^{n} \beta_{r j} \cdot R R_{A E}-j+U_{t}
$$

كه در آن RVAW، RVAI ، RVAA، RVAE، و رشد ارزش افزوده بخشهاى آب، كشـاورزى، صـنعت و بـرق، عرض از مبدأ، ضريب و Ut جزء اخلال مدل بيشنهادى هستستد. مدل اقتصادسنجى توسط نرمافزار ميكروفيت برآورد شد. نتيجه تخمسين معادلـه (N) بسه روش ARDL در جــدول (Y) ارائه شده است. تمام متغيرها در سطح اطمينان ه 9 درصـد معنسى

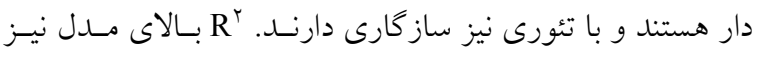


رابطه ارزش افزوده بخش آب با ارزش افزوده بخشهاى كشاورزى ...

\begin{tabular}{|c|c|c|}
\hline \multicolumn{3}{|c|}{ جدول †. نتايج تخمين متغيرهاى معادله تصحيح خطا } \\
\hline آماره t & ضريب & متغير \\
\hline س & $-0 / \Delta Y$ & dRVAA \\
\hline $1 / 99$ & $\circ / D Y$ & dRVAI \\
\hline $1 / 99$ & $0 / 4$ & dRVAE \\
\hline$-1 / 09$ & $-0 / 09$ & $\operatorname{ECM}(-1)$ \\
\hline \multicolumn{2}{|c|}{.$/ 9 V$} & $\mathrm{R}^{2}$ \\
\hline \multicolumn{2}{|c|}{$Y / \circ \wedge$} & D.W \\
\hline \multicolumn{2}{|c|}{$11 / 0 T$} & $\mathrm{~F}$ \\
\hline
\end{tabular}

ارتباط ميان متغير توليد ناخالص داخلسى و متغيرهـاى توضسيحى است، در جدول (†) ار ائه شده است. مطابق جدول (Y)، تمامى ضرايب متغيرها معنسىدار هستسند. يك درصد افزايش (كاهش) در ارزش افزوده بخش هاى صنعت،

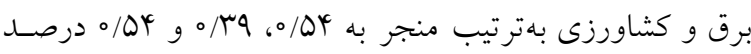
افزايش (كاهش) در ارزش افزوده بخش آب شد. در اين رابطـه، بخشهاى صنعت و برق بهترتيب بيش از بخش كشـاورزى بـر

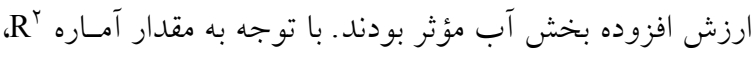
متغيرهاى توضيحى مـدل حسـود 99 درصــ از تغييـرات متغيـر وابسته را توضيح دادهاند.

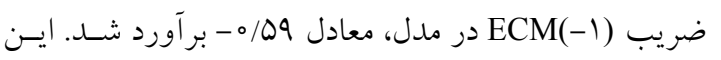
ضريب كه از نظر آمارى معنى دار است، نشان مى دهد كـه در هـر دوره، 09/ه درصد از عدم تعادل (انحراف) ارزش افزوده بخـش آنش

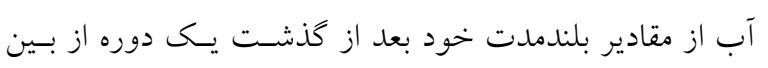
رفته است و در واقع در هر دوره، 09/ه درصد عـدم تعـادل در

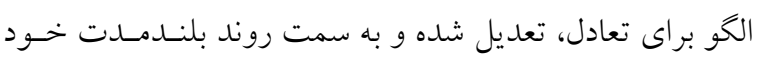

$$
\text { نزديك شده است. }
$$

نتايج تخمين كوتاهمدت و بلندمدت مــل نشـان داد كـه در بلندمدت، رشد ارزش افزوده بخش صنعت، بيشترين تأثير را بر رشد ارزش افزوده بخش آب داشت. ولى در كوتاهمـدت، رشـد ارزش افزوده بخشهاى صنعت و برق بهترتيب بيشترين تأثير را

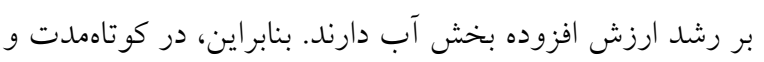
بلندمدت، رشد ارزش افزوده بخش كشاورزى تأثيرى منفى بـر
جدول Y. نتايج مدل ARDL

\begin{tabular}{|c|c|c|}
\hline آماره t & ضريب & متغير \\
\hline$-0 / 94$ & $-0 / 91$ & $\mathrm{C}$ \\
\hline$-1 / 44$ & $-0 / 91$ & dRVAW \\
\hline سזו- & $-0 / \Delta t$ & RVAA \\
\hline $1 / 99$ &.$/ D r$ & RVAI \\
\hline $1 / 99$ & $0 / r q$ & RVAE \\
\hline \multicolumn{2}{|c|}{.$/ 90$} & $\mathrm{R}^{r}$ \\
\hline \multicolumn{2}{|c|}{$r / \circ \Lambda$} & D.W \\
\hline \multicolumn{2}{|c|}{$\varphi / r \wedge$} & $\mathrm{F}$ \\
\hline
\end{tabular}

\begin{tabular}{|c|c|c|}
\hline آماره t & ضريب & متغير \\
\hline$-\circ / \Delta \Delta$ & $-0 / 10$ & $\mathrm{C}$ \\
\hline$-\circ / 0$ & $-1 / 0 V$ & RVAA \\
\hline$-0 / \wedge V$ & $r / 09$ & RVAI \\
\hline ס & $-0 / 19$ & RVAE \\
\hline
\end{tabular}

تمـامى ضــرايب ارائسه شــده در جــدول (r) داراى تفسـير بلندمدت هستند. هر ا درصد افزايش (كاهش) در ارزشافـزوده

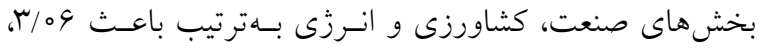
1/OV و ه ه ه هرصد افزايش (كاهش) در ارزش افـزوده بخـش آب مىشود. بنابراين، مى توان نتيجه كيرى كـــد كـه بـا افـزايش

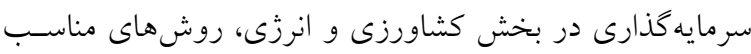
در صرفهجويى آب بايستى اعمال شود. بهمنظور بررسى روابـط كوتاهمدت بين متغيرهاى مــل، مــل تصسحيح خطـاى مربوطـه بهورت زير است:

$\mathrm{RVAW}=\mathrm{d} \alpha_{\circ}+\beta_{1} \mathrm{dRVAA}+\beta_{\gamma} \mathrm{dRVAI}$ $+\beta_{r} \mathrm{dRVAE}+\beta_{\varphi} \mathrm{ECM}$

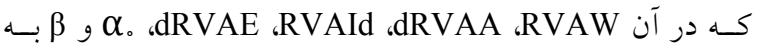
ترتيب رشــ ارزش افـزوده بخـش آب، تغييـرات رشــ ارزش افزوده بخشهاى كشاورزى، صنعت و بـرق، عـرض از مبـدأ و ضريب هستند. ضرايب مربوط به برآورد الخـوى تصسحيح خطـا كـه بيـانكر 
نشريه علوم آب و خاك (علوم و فنون كثاورزى و منابع طبيعى) / سال بيست و سه / شماره اول / بهار شجr|

جدول هـ مقادير ييشبينى شده ارزش افزوده بخشهاى آب، كشاورزى، صنعت و

برق استان مازندران (هزار ميليارد ريال)

\begin{tabular}{|c|c|c|c|c|}
\hline \multicolumn{4}{|c|}{ ارزش افزوده } & \multirow{2}{*}{ سال } \\
\hline برق & صنعت & كشاورزى & آب & \\
\hline$r / I V$ & $19 / r 1$ & $r \Delta / 91$ & D/Mr & 1491 \\
\hline$r / \mu r$ & $r \circ / M$ & rN/VI & $0 / \mu r$ & Irar \\
\hline$r / \omega_{0}$ & $r T / q V$ & $+1 / 4 \Delta$ & $\circ / \mu V$ & rar \\
\hline$r / 9 \mathrm{~V}$ & $r \Psi / 0 V$ & $x \psi / 1 \Lambda$ & $0 / 7 q$ & Irat \\
\hline$r / \Lambda r$ & $r 0 / 99$ & re/9r & $0 / 4 r$ & 1790 \\
\hline$r / 4 。$ & TV/TG & $149 / 90$ & $0 / 4 y$ & 1799 \\
\hline$r / I V$ & YN/AQ & $\Delta r / M q$ & $0 / 49$ & $1 \mathrm{rav}$ \\
\hline$r / \mu r$ & $r 0 / 40$ & $\Delta D / T$ & $0 / 49$ & 1 ran \\
\hline$\varphi / 0$ 。 & $r Y / 04$ & $\Delta V / N Q$ &.$/ 01$ & 1799 \\
\hline $4 / 99$ & $\pi r / 94$ & $90 / 90$ & $\circ / \Delta r$ & 1400 \\
\hline
\end{tabular}

ارزش افزوده بخشهاى كشاورزى، صنعت و برق با بخش آب رشد ارزش افزوده بخش آب دارد.

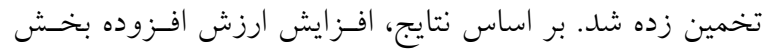

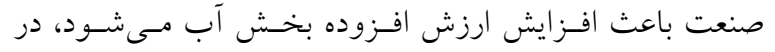

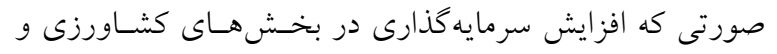

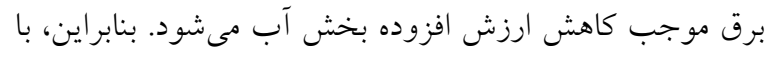

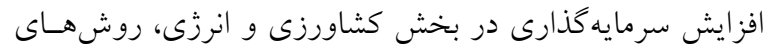

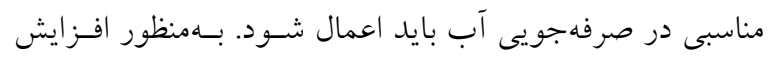

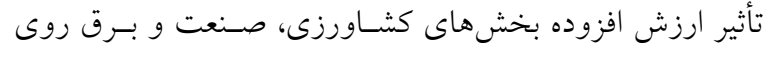

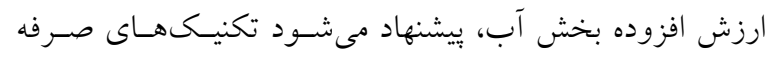
جويى مصرف آب در بخشهاى فوق اعمال شود. ارتقاى بهرهورى آب مستلزم برنامهريزى دقيق و اجر ایى صحيحتر آن اسـت.

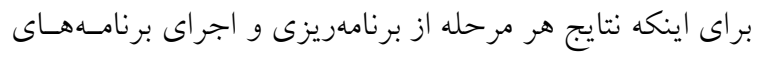

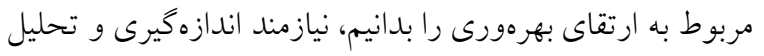

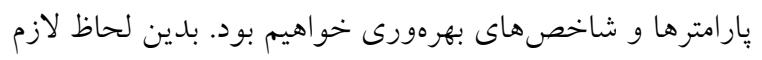

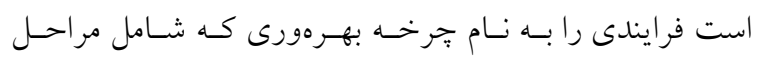

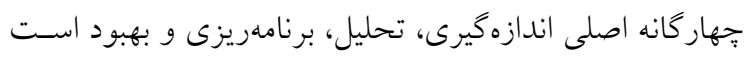
براى حصول به موفقيت، بهكار بست.

بيشبينى ارزش افزوده بخشهاى مختلف

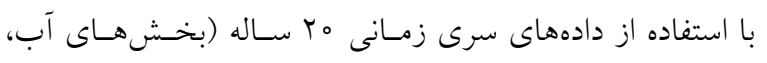

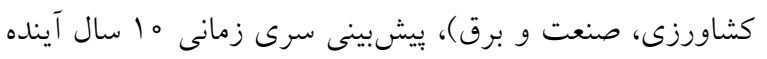

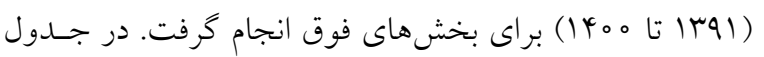

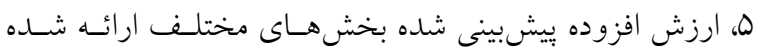

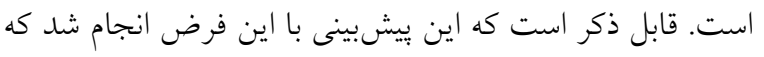
شرايط حاكم بر بخشهاى ذكر شده مشابه شرايط فعلسى باشـد.

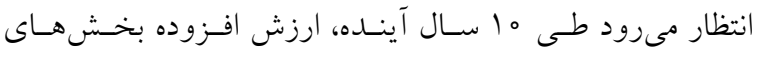

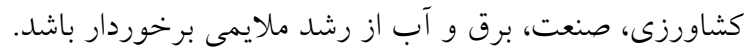

\section{نتيجه گيرى}

در اين تحقيق، تأثير رشد ارزش افزوده بخشهـاى كشـاورزى،

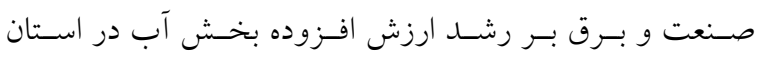

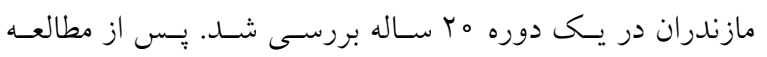

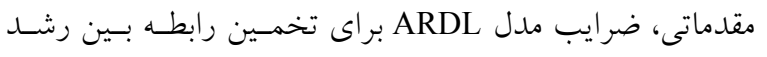


1. Abdin A. E., I. Gaafar. 2009. Rational water use in Egypt. pp. 11-27. In: El Moujabber, M., Mandi, L., TrisorioLiuzzi, G., Martín, I., Rabi, A., Rodríguez, R. (Eds.). Technological Perspectives for Rational Use of Water Resources in the Mediterranean Region. Bari: CIHEAM, Options Méditerranéennes: Série A. Séminaires Méditerranéens.

2. Ahangari, A. and S. Kamranpour. 2016. Effect of financial development and added value on energy consumption in industrial and agricultural sectors of Iran. Journal of Applied Economic Studies 5(19): 286-269.

3. Akbarian, R. and A. Ghaedi. 2011. Investment in economic infrastructure and study of effect on economic growth. Journal of Economic Growth and Development Research 1(3): 11-48.

4. Ansari Y., S. and A. Hosseini Yekani. 2014. The effect of financial market development on agricultural growth using ARDL. Agricultural Economics and Development 22(85): 237-254.

5. Banerjee, A. J., J. Dolado and R. Mester. 1992. On Some Simple Test for Cointegration: The Cost of Simpilicity. Bank of Spain Working Paper, No. 9302. Spain.

6. Baradaran, A. and G. Zomorodian. 2017. Examining the effect of shocks in monetary and fiscal policy on value added of industry and mining sector in Iran. Journal of Investment Knowledge 6(24): 117-138.

7. Barbier, E. B. 2004. Water and Economic Growth. The Economic Record. 80(248): 1-16.

8. Darzi, A., S. Rafee Rad, M. Khoshravesh, A. Asgari and M. R. Babaee. 2014. Determination of Water Sharing to Mazandaran Province GDP Regarding to Water Unit Consumption. Final Research Report, Mazandaran Regional Water Authority. Mazandaran.

9. Doss, M. and G. Milne. 2001. Water as Economic Good. In: Proceeding of the Beijer Workshop on "Property Rights Structures and Environmental Resource Management” in Egypt. Egypt.

10. Ehsani, M. and H. Khaledi. 2004. Identify and prosper of agricultural water productivity in order to improve country water and food security. In: Proceeding of the $11^{\text {th }}$ Seminar of Iranian National Committee on Irrigation and Drainage. Tehran.

11. Gholizadeh, H. and A. Saleh. 2005. Study of total productivity of production factors in Iran's economic sector in 1978-2002 (with emphasis on agriculture and investment role). Iranian Journal of Agricultural Sciences 36(5): 1131-1141.

12. Hoekstra, A. Y. and P. Q. Hung. 2005. Globalisation of water resources: International virtual water flows in relation to crop trade. Global Environmental Change 15: 45-56.

13. Jlayeri, M. 2002. Study of renewable national resources on GDP. MSc. Thesis, University of Sistan and Baluchestan. Iran.

14. Kazumi, Y. and O. Yasuhiro. 2003. A Message from Japan and Asia to the Word Water Discussions. The Japanese Institute of Irrigation and Drainage (JIID). Japanese.

15. Keshavarz, A. and N. Heydari. 2004. A review in production and consumption of agricultural production. In: Proceeding of the $1^{\text {st }}$ Symposium of National Resources Loss Prevention. Tehran.

16. Latif, B. 2001. Water resources remedy role in Iran economy. In: Proceeding of the $1^{\text {st }}$ Symposium of National Resources Loss Prevention. Tehran.

17. Manzor, D. and S. Shovalpoor Arani. 2009. Relationship of electricity sector with other economic sectors. Iranian Journal of Energy 12(30): 89-97.

18. Mirzaee Khalil Abadi, H. R. and H. Abrishami. 2007. The role of water in agriculture sector development. In: Proceeding of the $6^{\text {th }}$ National Conference of Agricultural Economics, Mashhad.

19. Pesaran, B. and H. Pesaran. 2009. Time Series Econometrics, Using Microfit 5.0 Oxford University Press. England.

20. Pesaran, H. and B. Pesaran, 1997. Working with Microfit 4.0: Interactive Econometric Analysis", (DOS and Windows versions), Oxford University Press. England.

21. Shahnoushi, N., S. Saghaian, M. Reed and F. Hayatgheibi. 2013. Value of water in an arid area of central Iran. Journal of Basic and Applied Scientific Research 3(9): 401-407.

22. Shiklomanov, I. A. and J. C. Rodda. 2003. World Water Resources at the Beginning of the Twenty First Century. Cambridge University Press, Cambridge, UK.

23. Van der Zaag, P. and H. H. G. Savenije. 2006. Water as an Economic Good: The Value of Pricing and the Failure of Markets. UNESCO-IHE Institute for Water Education, Value of Water Research Report Series No. 19. The Netherlands.

24. Ward, F. and A. Michelsen. 2002. The economic value of water in agriculture: Concepts and policy applications. Water Policy 4: 423-446. 


\title{
Relationship between the Added Value of Water Sector and the Value of Agriculture, Industry and Electricity Sectors in Mazandaran Province
}

\author{
A. Darzi-Naftchal ${ }^{1}$, S. Rafierad ${ }^{2}$, M. Khoshravesh ${ }^{1 *}$, A. Asgari $^{1}$ \\ M. R. Babaei ${ }^{3}$ and H. Zabardast Rostami ${ }^{1}$
}

(Received: September 10-2016 ; Accepted: January 24-2018)

\begin{abstract}
Water is a vital source for both human and biological living. Today, water management and conservation, not only both in developing countries but also in and the developed countries ones, has is of great importance. In the traditional economy, water is not considered as a productive factor in the national accounts; however, but in reality, water is the primary factor in many direct and indirect goods and services. To evaluate the effect of growth in the added value of agriculture, industry and electricity sectors on the added value of water sector in the Mazandaran province, coefficients of ARDL model were estimated using the Micro fit software. The extended Dickey-Fuller unit root test was used for the statistical test of variables. The static test of variables showed that all variables were significant at the $95 \%$ confidence level and were also consistent with the theory. A 1\% increase (decrease) in the added value of industry and electricity resulted in the increase of $0.54 \%$ and $0.39 \%$, respectively, increase (decrease) in the added value of the water sector, respectively. Also, 1\% increase (decrease) in the added value of the agricultural sector caused in a $0.54 \%$ increase (decrease) in the added value of the water sector. Industry and electricity sectors affected the added value of water sector more than agriculture. In the long-term, the growth of the added value of the industry sector had the greatest impact on the growth of the added value of water sector. Based on the results, controlling water use in agriculture, industry and electricity sectors increases increased the effects of the added value of these sectors on the added value of the water sector.
\end{abstract}

Keywords: Economy, Production, Merchandise, ARDL model

1. Department of Water Engineering, Sari Agricultural Sciences and Natural Resources University, Sari, Iran.

2. Agricultural Planning, Economic and Rural Development Research Institute, Tehran, Iran.

3. Payam e Noor University, Mazandaran

*: Corresponding Author, Email: khoshravesh_m24@yahoo.com 